\title{
La insistencia de los cuerpos: el signo mujer proletaria en la narrativa de Nicomedes Guzmán*
}

\author{
Insistence of the body: Representation and the proletarian \\ woman sign in the narrative of Nicomedes Guzman
}

Ana María Cristi C.*

\section{RESUMEN:}

El presente artículo tiene como objetivo analizar las variantes

Palabras clave: estéticas y políticas que confluyen en el signo mujer proletaria en la narrativa del escritor chileno Nicomedes Guzmán (19141964). La propuesta de lectura aquí desarrollada posiciona a los personajes femeninos proletarios de Guzmán como nuevos Nicomedes Guzmán, mujer proletaria, cuerpo, maternidad, signo. agentes revolucionarios que, mediante el cuerpo y la maternidad, logran tensionar o hacer huir las jerarquías políticas, sociales y culturales tradicionalmente concebidas en torno a la mujer.

\begin{abstract}
:
This article aims to analyze the aesthetic and political variants that converge within the proletarian woman sign in the narrative of Chilean writer Nicomedes Guzman (1914-1964). It proposes a reading that positions Guzman's proletarian female characters as new revolutionary agents who, through the body
\end{abstract}

\author{
Keywords: \\ Nicomedes \\ Guzmán, \\ proletarian \\ woman, body, \\ motherhood, sign
}

\footnotetext{
El presente artículo surge de la tesis de la autora para obtener el grado de Magíster en Literatura en la Universidad de Playa Ancha, Valparaíso, Chile y se enmarca en el proyecto Fondecyt Iniciación n 11160327 : “Literatura y multitud: cartografía conceptual de la narrativa de Nicomedes Guzmán desde la perspectiva crítico-clínica de la filosofía de Gilles Deleuze y Félix Guattari" (2016-2019), en el cual participó como ayudante de investigación. Investigador responsable Dr. Patricio Landaeta Mardones. La autora agradece al Dr. Landaeta por el apoyo en el desarrollo de esta investigación; así como a su director de tesis, Dr. Alexis Candia Cáceres, por la orientación y la asistencia en el proceso investigativo.

** Chilena. Estudiante del Doctorado en Literatura de la Pontificia Universidad Católica de Chile. Magíster en Literatura por la Universidad de Playa Ancha y Licenciada en Filosofía por la Pontificia Universidad Católica de Valparaíso. arcristi@uc.cl
} 
Lainsistenciadeloscuerpos:elsignomujerproletariaenlanarrativadeNicomedesGuzmán | Cristi

and motherhood, manage to challenge or ward off the political, social and cultural hierarchies traditionally conceived around women. 


\section{Introducción}

Durante el siglo XIX la imagen de la mujer en la literatura chilena se caracterizó por responder a los convencionalismos patriarcales que predominaron en la época. De entrada en el siglo XX, la representación de las mujeres continuaba respondiendo a un código sociocultural masculinista, esbozándose frecuentemente desde la carencia de toda agencia política, económica y social. Esta mirada, por ejemplo, se evidencia en importantes novelas fundacionales como Martín Rivas (1862) de Alberto Blest Gana o Casa Grande (1908)de Luis Orrego Luco, donde las mujeres "de bien" son representadas sobre la base de la conformación familiar tradicional, siendo madres por antonomasia, fiel reflejo del "ángel del hogar" y símbolo del Estado nación. Lejos de esto, las mujeres del "bajo pueblo" son escasamente mencionadas en la literatura, siendo la mayoría de las veces personajes que representan los vicios y defectos de una multitud silenciada que, aparentemente, carece del goce de clase, formación y educación.

Sin embargo, entre 1930 y 1960 dicha representación del pueblo y la mujer logra ponerse en cuestionamiento, sobre todo con la propuesta estética-política de la generación del 38, cuyos miembros -interesados por el diálogo que surge del realismo social, las vanguardias latinoamericanas y la cultura popular-, cuestionan el trabajo literario realizado en torno a lo nacional y los convencionalismos con los que usualmente se representaba al pueblo chileno. Entre los escritores y escritoras que conforman la generación del 38, Nicomedes Guzmán (1914-1964) destaca como una de las figuras más prolíficas. Autodidacta de formación, su escritura no solo sobresale por interesarse en la vida de los más desposeídos de la ciudad, la pampa salitrera o los cerros de Valparaíso, sino que también por contribuir a un interesante proyecto literario que buscaba reformular estéticamente la concepción de pueblo, multitud e identidad nacional. Así pues, siguiendo la visión crítica de escritores como Baldomero Lillo, Carlos Sepúlveda Leyton, Jacobo Danke o Alberto Romero, Nicomedes Guzmán incluye en su trabajo narrativo al pueblo obrero desde la legitimación de "lo proletario". Su obra narrativa se despoja de la retórica sensacionalista del naturalismo (Guerra, "El conventillo" 126) con la intención de deslegitimar la perspectiva distante y negativa con la que de antaño se configuraron los espacios suburbanos y "sus" gentes en la produc- 
ción literaria nacional. En esta línea, la mujer popular que antaño solo figuraba en los márgenes de la prostitución, el alcoholismo y la delincuencia, ahora es visualizada desde un nuevo enfoque social, donde se enaltece su participación en el trabajo, su rol de madre proletaria y su compañerismo con el obrero.

A pesar de la riqueza que se advierte en la propuesta literaria de Guzmán, los estudios en torno a su narrativa son escasos. La mayoría de los que se han realizado hasta la fecha se concentran en la representación del conventillo en sus dos principales novelas: Los hombres oscuros (publicada en 1939) y La sangre y la esperanza (publicada en 1943), dejando un gran espacio en blanco respecto del resto de su obra. Ciertamente, son pocas las menciones que se han hecho acerca de otras temáticas presentes en la narrativa de Guzmán, siendo la representación de la mujer una de las tantas aristas que quedaron al margen del estudio que se ha registrado en torno al escritor. El investigador norteamericano Lon Pearson (1976) dedica un pequeño apartado a la representación de la mujer obrera en la obra de Guzmán, advirtiendo cierta dificultad por parte del escritor para lograr un "verdadero" acercamiento a la mujer proletaria. Algo que, en cierta manera, discute Karim Rosemblatt (2000) al considerar a las mujeres de La sangre y la esperanza como excelentes representantes del proyecto sociopolítico izquierdista de la época (185). Según Rosemblatt, "Guzmán sketched his view of proletarian female virtue, placing allegiance to class at the epicenter of feminine decency" (186). Lejos de esto, María Fernández Smits (2011) vuelve a la mentada novela de Guzmán para ejemplificar su posición crítica respecto de la naturalización de la violencia doméstica en la literatura chilena de principios del siglo $\mathrm{XX}$, dando cuenta del retrato del hombre que "abusa de la superioridad que socialmente tenía como hombre" (64). Esta perspectiva es compartida por Camila Álamos Mubarak (2015) quien elabora una tesis acerca de la posición subordinada y denigrante de la mujer en la novela. Álamos atiende al desarrollo de los estereotipos femeninos de madre/dueña de casa y prostituta y sostiene que "ambos tipos de mujer sufren degradación corporal producto de su cosificación" (37) en la obra de Guzmán. Será Lucía Vásquez (2017), nieta del escritor, quien desarrollará un análisis menos interpelativo en torno a las mujeres en la narrativa de Guzmán. Según Vásquez el escritor - aún circunscrito en una cultura machista-logra integrar a 
las mujeres obreras en su proyecto estético-político en el cual busca destacar la belleza del pueblo chileno.

El presente artículo analiza la construcción literaria de la mujer proletaria presente en la narrativa de Nicomedes Guzmán. Interesa dar un giro crítico a la representación para comprender a la mujer proletaria como un signo. De este modo, atendiendo a las variables estéticas, culturales e ideológicas que convergen en la narrativa de Guzmán, se propone escenificar al cuerpo y la maternidad de la mujer como una línea de fuga que, alejada de su imagen tradicional, permita pensar a las proletarias como partes fundamentales de una nueva subjetividad emancipada-revolucionaria que intenta esbozar el escritor.

\section{Construcción literaria de las proletarias: madres, obreras y prostitutas}

En la literatura la mujer es representada mediante signos que configuran su identidad. En su conjunto, estos signos esbozan un perfil característico de la mujer y la femineidad basados en la premisa de la ausencia, la carencia y la otredad. En un constante juego de polaridades lo femenino es devaluado y subyugado ante la sobrevaloración de lo masculino. Es en este panorama que se comprenden las dinámicas culturales en torno a la concepción de género y, más aún, alrededor de la idea de patriarcado. No por otra cosa las construcciones identitarias elaboradas en torno a la mujer se comprenden en estrecha relación con el imaginario masculino, el cual configura parte importante de los discursos que circunscriben las artes, las letras y la cultura.

Tanto en la literatura como en la metanarrativa el signo mujer ha sido tradicionalmente entendido como representación, o más bien, bajo el dominio de la representación, toda vez que este adquiere su función y significado mediante el uso que se le otorgue en la sociedad. En el ensayo de Lucía Guerra La mujer fragmentada: historias de un signo (2006) es posible observar, mediante un minucioso trabajo de recopilación y análisis, cómo la mujer ha sido imaginada desde la polarización simbólica que divide y contrasta lo femenino con lo masculino. Según Guerra, la mujer es concebida como el estandarte de los modelos sociales y culturales propuestos por el sujeto masculino y el imaginario falogocentrista. De ahí que, según la escritora, "la creación 
de los personajes literarios se nutra, en gran medida, del signo mujer prevalente en una etapa particular de la historia oficial y sus discursos dominantes" (31). Para hablar del signo mujer, desde la perspectiva de Guerra, hay que considerar su dualidad de significado-significante, para luego comprender que el signo "existe como sustitutivo verbal del objeto mismo, él es la unidad que divide el mundo entre lo presente tangible y lo representado" (130). En este sentido, el signo mujer se presenta como una compleja construcción cultural que hace de ella (la mujer) una fuente de inagotables modelizaciones imaginarias negativas cuya presencia se observa transversalmente en el arte, la literatura, la filosofía y la cultura en general.

Nicomedes Guzmán esboza singulares características respecto del género femenino, las cuales se relacionan con el imaginario genéricopatriarcal que predominaba en la época. Por una parte, al igual que en gran parte de la literatura latinoamericana, la narrativa de Guzmán bosqueja personajes femeninos que reproducen los históricos arquetipos de la mujer, mientras que por otra, su narrativa tensiona dichos arquetipos sacando a las mujeres de los lugares comunes para presentarlas desde otra perspectiva menos tradicional. Si algunas veces, ante el heroísmo del obrero, se destaca el sentimentalismo, la honestidad y la ternura de la mujer proletaria, otras veces, ante la ausencia del varón, se emergerá el brío, la valentía y el esfuerzo de las mujeres que, ante de adversidad, toman el rol de sostenedora y pilar fundamental de la familia.

La mujer proletaria en su rol social y biológico de madre es fundamental en la narrativa de Guzmán. La maternidad es una de las características más desarrolladas por el escritor respecto de sus personajes femeninos. Las madres usualmente son aquellas mujeres abnegadas, luchadoras y valientes que, a pesar de las adversas circunstancias de la pobreza, demuestran incansable vitalidad para cuidar de sus hijos, la familia y el hogar. Desde la perspectiva de la "mujer-matriz" ( GuerraCunningham, "El personaje" 6), la proletaria cumple con la función generadora de vida, cuidado y perpetuación. A pesar de no constituir "-en el contexto de su representación discursiva - una imagen de autoridad ni de derecho, sino una figura afectiva, dedicada solo al cumplimiento de su deber para con los otros" (Montero 72), la madre es idealizada como la figura que representa, al igual que el obrero, la potencia de la revolución moral, ideológica y social. Una imagen que 
Enrique, el narrador de La sangre y esperanza (2014), describe con ternura y emoción:

Ella era una mujer. Una extraordinaria mujer con los zapatos empapados, con el delantal también empapado sobre el vientre y los pechos tibios, con las manos encarrujadas, reblandecidas por el desmanche, con los brazos enrojecidos por el frío, con el moño un poco caído, con los ojos tristes... era mi madre. (152)

Laura, la madre, como cualquier obrera doméstica representa el brío de la mujer proletaria. Lavando ropa por encargo, cuidando de los hijos, solidarizando con las vecinas maltratadas, apoyando al marido, será ella quien encarnará el rol de la madre obrera. A pesar de que "las tareas de cuidado son consideradas las tareas más típicamente femeninas, por ello mismo se biologizan como una continuación del rol de madre y se ignoran como trabajo" (Juliano 94), en la narrativa de Guzmán las madres son valoradas por aportar, desde el trabajo doméstico, al sustento del hogar cuando las circunstancias así lo requieran. No por otra razón la maternidad obrera es visualizada como un "heroísmo femenino". Esta apreciación también se observa en La luz viene del mar (1963), la última novela de Guzmán, donde da cuenta entre otras cosas de la difícil vida de una madre viuda en el norte chileno: "Sofía, la viuda madre, inició sus luchas por el pan, contra el medio espantoso que se sintetizaba en la lasciva agresividad de los hombres, lavando, cocinando, sirviendo como perra guardiana silenciosa y heroica" (61). Las madres obreras tienen, en este sentido, la capacidad "viril" de habérselas con el complicado panorama social y económico que constantemente las maltrata, trabajando por sus hijos y su familia hasta que su cuerpo así lo permita.

Dicha cualidad viril de las madres proletarias también se observa ligada a la sublimidad. Un sentimiento que se comprende como una compleja relación entre el placer y displacer que agita y excita la belleza hacia un límite en el cual solo acontece la imposibilidad de aprehenderla en su totalidad (Žižek 258). Tensionando las lecturas más idílicas en torno a las madres obreras, como las anteriormente mencionadas, Guzmán también retrata a la maternidad desde esa otra belleza marcada por la pobreza, el vicio y la marginalidad. Así, por ejemplo, en cuentos como "Destello en la bruma" (publicado 1944) y "Leche de burra" (publicado en 1954) se observan complejas 
relaciones filiales entre madres e hijas que comparten la fatalidá ${ }^{1}$ de una vida envuelta en el abandono, el dolor y la resignación. En ambas narraciones, se presentan mujeres solitarias que resisten en la esperanza de un "futuro mejor" junto a un hombre que las contenga. Ante la imposibilidad de dicho futuro, será la comprensión entre madre e hija aquello que, "como un gesto natural de vida" (Destello 96) se imponga al desconsuelo de la soledad y la miseria. En efecto, Guzmán muestra mediante la figura de la madre, los distintos momentos de ternura que aún entre la sordidez del conventillo y la pobreza de los cités, surgen como "la piedad encinta de esperanza" (Destello 96) que contrarresta la destrucción de los vínculos afectivos derruidos por la marginalidad.

La obrera es otra figura importante en la elaboración del signo mujer proletaria en la narrativa de Guzmán. Su rol en los cuentos y novelas del escritor es distinto del de los varones. A pesar de transitar por los espacios de la fábrica, el comercio o el trabajo doméstico por encargo, es interesante considerar que ella, aparentemente, no figura como un agente activo de la emancipación revolucionaria, pues carece de voz y discurso respecto de la problemática de clase, lucha y reivindicación proletaria. Esto se comprende, según Barbara Foley (1993), porque "the representations of gender in proletarian fiction both reflect and reproduce the left's contradictory theory and practice with regard to the women question" (231). Las obreras se caracterizan por ser mujeres nobles llenas de humildad y sacrificio, no obstante en comparación con el "ideal de obrero", nunca se le observa como un verdadero agente político de cambio.

En Los hombres obscuros se observan interesantes escenas que dan cuenta de la nobleza de la mujer obrera. Mediante las apreciaciones de Pablo, un joven lustrabotas, se logra advertir las cualidades de Inés, la obrera de quien se enamora y por quien cambia para convertirse en un aliado de la Revolución. La sencilla belleza de Inés despierta

La fatalidad es uno de los tópicos más recurrentes en la literatura criollista y regionalista. Se caracteriza por la subordinación de los personajes tanto al paisaje como al destino. La fatalidad es una cierta incapacidad de ejercer dominio sobre la vida, y desde allí, aceptar los sucesos del pasado como parte inexorable del destino. Según Lorena Amaro (2014) "La fatalidad se presenta como un rasgo de los personajes imposibilitados para hacerse cargo de sus vidas y sus decisiones” (76). 
en Pablo un sentimiento de admiración, que en el transcurso de la narración se convierte en deseo, pasión y amor: "acaricio sus manos. Mis manos obreras de macho acarician y gozan del contacto de esas manos obreras de mujer. [...] la beso [...] beso también sus manos, sus manos bajo cuya obrera suavidad la ternura hace sentir" (62). La condición de obrera de Inés es signada en la novela como una de las características más nobles de su femineidad. Ella, a pesar de estar en el mundo varonil de la fábrica, transita por dicho espacio sin romper con su singularidad de género. Inés sigue presentándose con las cualidades femeninas que el escritor esboza en el resto de las mujeres dignamente proletarias.

Algo similar ocurre con Elena, la hermana de Enrique en La sangre y la esperanza. Si bien Elena es una obrera más de las tantas que habitan en el cité capitalino donde vive la familia Quilodrán, su participación en la actividad política no es manifestada en todo el transcurrir de la novela. Elena se caracteriza por ser una joven responsable con su familia y virtuosa en sus labores de cuidado. Su conformación como personaje literario es complejo de identificar, pues tal como señala Lon Pearson (1976) sus acciones y discursos son conocidos a través del recuerdo del narrador y serán sus apreciaciones personales las que primen en el relato: "the narrator is inclined to help the reader whenever he wants to emphasize proletarian integrity"(215). Sin embargo, en el apartado "Elena" hay una serie de cartas escritas por ella cuyo destinatario es el poeta Abel Justiniano. Allí, Elena manifiesta su interés por aprender sobre la Revolución y lo importante que es para ella leer las reflexiones políticas de su amado: "Yo fui a la conferencia, ¿vas a creerlo? [...] todo lo que expusiste me revoloteaba la cabeza. Pero venía feliz. La gente parecía entenderte muy bien. Me enorgullecía la atención que todos tus camaradas ponían a tus palabras" (cursivas en el original 260). Y agrega: "Me alegro de que, después de tu tarjeta, me hayas mandado una copia de tu trabajo. Leído con calma, me ha encantado. Tengo mucho que aprender de lo que alli dices" (cursivas en el original 260). Es interesante observar que Elena comienza su proceso de concientización social mediante las palabras de Justiniano y no a través de su trabajo en la fábrica. Su condición de obrera asalariada no significa, necesariamente, participar de los intereses políticos de su clase, aun cuando su padre es un importante líder sindical. 
Así pues, tal como sucede en variadas novelas sociales, se advierte cómo el escritor esboza en sus personajes femeninos la incapacidad de discurso propio o capacidad reflexiva respecto de la lucha política, social y económica del proletariado. Se comprende así que "female characters seem to stand merely as mute symbols of capitalism's double exploitation of the labor power and domestic work women. Even when women do speak in public, [...] their speech is modulated through the voices and words of men" (Rabinowitz 108). No por otra cosa la importancia de Elena en la novela estará signada en su rol de futura madre (y de allí la esperanza) y no en el de obrera.

De modo diferente las prostitutas contribuyen a la compleja configuración del signo mujer proletaria. Estos personajes, usualmente anónimos, representan los vicios y morbosidades del pueblo trabajador. Mediante su escenificación es posible advertir cómo el escritor las relaciona con una de las tantas problemáticas sociales que tienden a subyugar la potencia vital y emancipadora de la multitud. Las prostitutas se presentan como la contrafigura de la madre abnegada y la noble obrera asalariada siendo, en este sentido, aquello que contradice o fisura la tan apreciada dignidad moral de la familia proletaria. En las tres novelas de Nicomedes Guzmán se observa la presencia de las prostitutas. En Los hombres obscuros las prostitutas figuran como uno de los tantos componentes humanos que habitan el conventillo. Su presencia en la narración se advierte en los distintos momentos en los que Pablo pone de manifiesto su deseo sexual no satisfecho. Al no poder consumar su deseo con Inés, Pablo piensa en las prostitutas como una dolorosa alternativa: "me quedo como un muerto bajo la noche inquieta y pestañeante. Y no sé por qué, pienso con dolor en las rameras del suburbio" (83). Pablo incurre en el comercio sexual tras las constantes negativas de Inés. Será la pequeña Rebeca, una muchachita huérfana (92) y sin esperanzas, la que servirá de cuerpo y placer para acallar el instinto de Pablo. En La sangre y la esperanza, en tanto, las prostitutas serán esbozadas desde la inocencia de Enrique quien, dando vida a sus recuerdos de infancia, indica: "Yo no comprendía aún exactamente la función de las prostitutas [...] la curiosidad me llevó hasta la puerta de la casa de Sergio. Era una casa sórdida. De altos, hedionda a jabón barato o a ratones" (75-76). Al igual que en su primera novela, Guzmán utiliza a las prostitutas para dar cuenta de las precarias vidas que subsistían en aquellos espacios reducidos del cité o el conventillo, 
aquellas "mujeres haraposas y pintarrajeadas" (141) que "reían con risa estruendosa" (142) se presentan como el gran misterio sexual ante los ojos de Enrique. En ambas novelas, ya sea desde el deseo o desde la curiosidad, serán las prostitutas aquellos cuerpos femeninos abyectos que exteriorizan toda la miseria del proletariado.

En La luz viene del mar, a diferencia de las dos novelas anteriores, se exterioriza la ideal del burdel. Las prostitutas en el norte de Chile se presentan como resultado de las múltiples miserias que deben sufrir algunas mujeres en el desierto. Ellas serán el objeto de placer y deseo para los trabajadores pampinos: “A sobajear mujeres bajamos de la pampa, que harta falta nos hacen sus cositas!” (116). Ellas, las tristes mujeres de la noche, a quienes les "ardían las células bajo la invasión de las caricias" (175), se advierten en la novela de Guzmán como las compañeras del vicio y la degeneración de los obreros. Estos, explotados por largas jornadas de trabajo, buscan en las mujeres una noche de diversión, compañía y cariño. En este contexto, el prostíbulo de la "Siete dedos" se convierte en un turbio paraíso para los varones nortinos: "sudaban las hembras y al término de cada baile se echaban en los divanes floreados, suspirando, acezando. Reían y palmoteaban los hombres semiborrachos [...] en integridad total, con cuerpos, movimientos, rostros, agitación, alegría: humanidad distendida" (245-246). Las mujeres conforman un espacio de entretenimiento nocturno que termina por degradarlas hasta el límite de la mera cosificación corporal. El cuerpo femenino es el refugio para los navegantes, comerciantes y obreros del norte. A diferencia de la de conventillo, la prostituta de burdel se inserta dentro de un sistema de jerarquías donde destaca la figura de la "cabrona". Las mujeres aquí habituadas se desmarcan de los roles sociales femeninos tradicionales donde, aparentemente, la conformación de la familia resulta ser un acto de responsabilidad moral fundamental. Un rasgo que no solo se visualiza en las novelas burguesas, sino que también se observa en las propias ficciones proletarias $^{2}$.

\footnotetext{
2 En este sentido, cabe destacar la figura del "héroe proletario" que, cumpliendo con los propuestos clásicos de la narrativa social, también se advierte en algunos cuentos de Nicomedes Guzmán. Este héroe se caracteriza por salvar a las prostitutas de su degradación social. En "Solo unas cuantas lágrimas" se observa cómo un obrero defiende a su enamorada tras ser amedrentada por su antiguo trabajo de prostituta, dándole de este modo sentido y esperanza a su nueva vida. Igualmente, en "Soledad" una prostituta,
} 


\section{Las que no tienen voz: el cuerpo como manifiesto}

Los personajes femeninos que constituyen la narrativa de Guzmán son configurados, según parece, desde una compleja relación que versa entre literatura y marxismo asumiendo, de este modo, estereotipos femeninos tales como la madre, la obrera y la prostituta. A pesar de que el escritor rompe con ciertos convencionalismos negativos esbozados en la literatura nacional en torno a la mujer popular, esta pareciera seguir representada desde la diferencia asimétrica con el varón, sobre todo respecto de la delimitación de espacios (público y privado) y la capacidad de agencia política. En gran parte de la obra de Guzmán, la mujer proletaria sigue vinculándose con el hogar y la maternidad, mientras que por el contrario, el varón lo hace con el espacio público, el trabajo y la actividad política. La segmentación entre ambos lugares y sus respectivas correspondencias genéricas permite advertir cómo los espacios y sus respectivas relaciones basadas en la diferencia de género configuran pensamiento, discurso y acción política.

La conexión entre espacio y pensamiento se advierte en la narrativa de Guzmán tras la insistencia del escritor por relacionar a la mujer con el cuerpo, el instinto y la intuición. Nombrando a la mujer como "perra" o "hembra" el escritor da cuenta de la delimitación de esta a un estado natural, muy propio de la época en la que escribe, en la que la mujer es considerada usualmente desde la exclusividad de su diferencia biológica. El hembrismo ${ }^{3}$ presente en la narrativa de Nicomedes Guzmán responde a las relaciones híbridas que sustentan su posicionamiento estético. La convergencia entre las vanguardias latinoamericanas, el realismo social y la cultura popular se hace presente en la mayoría de los libros del escritor. Esta situación se comprende al analizar el vínculo que surgió entre el virilismo y la vanguardia en la región, cuyo apogeo se advierte en el advenimiento del futurismo italiano

luego de sufrir diferentes humillaciones junto a su hija, recibe una segunda oportunidad en la vida al ser amada y respetada por un noble italiano.

3 En tanto concepto, el hembrismo según la Encyclopedia of race, ethnicity and society (2008), se define como: "In most societies, female and male roles are considered complementary; in Hispanic cultures, machismo refers to essentially male or masculine attributes and behaviors, while hembrismo pertains to matters feminine. Some note that just an as machismo may be seen as an exaggerated sense of masculinity, hembrismo is the feminine quality of being excessively submissive and subservient to men. The two concepts must be considered in concert (863). 
tanto en México como en Perú a principios del siglo XX. Allí, se promulgó con insistencia la búsqueda del superhombre y se ahondó en el culto a la guerra y el patriotismo, algo que tuvo como contrapartida la configuración complementaria de una estética femenina en la cual la mujer vuelve a su estado natural, realzando la figura de la paridora o la nutridora con la intención de sobrevalorar la virilidad del varón. Esta perspectiva, muy relacionada con la propia cultura popular, contribuye a un imaginario cultural que se refleja en los folletines, canciones y distintas manifestaciones locales en las que el machismo es posicionado y valorado como estandarte de reconocimiento y poder.

En La carne iluminada (1945) se muestra con claridad esta relación entre animalidad y mujer. El escritor destaca la condición biológica de la mujer y su correspondencia con la naturaleza y lo primitivo. En "Rapsodia en luz mayor" se relata la historia de Gabriela quien, desde el norte de Chile, viaja a Valparaíso junto con su esposo en busca de una vida mejor. Allí, entre los cerros del puerto, la mujer es abandonada, quedando sola con sus dos hijos. La ausencia de su esposo pareciera volverla débil, pequeña y sufriente. Los recuerdos de tiempos pasados la envuelven en un estado de nostalgia permanente: "Gabriela pensaba en una voz, ni ruda ni amable, pero viril, masculina, enérgica, capaz de mandar, de dominar, de seducir, de doblegar a costa de varonil y levemente áspera ternura [...] lo que ella amaba y adoraba todavía" (20-21). Dicha nostalgia, teñida por un sentimiento de invalidez, muestra al personaje femenino desde una clara diferencia genérica cuyo apogeo se observa en la propia configuración sociocultural de la época.

Aludiendo a la animalidad de la proletaria, Guzmán no duda en usar dicha expresión para referirse a Gabriela en contextos de excitación anímica, tal como sucede tras su reencuentro con el marido: "le hubiera mordido la nariz al esposo, la nariz o la oreja, como ella estaba indistintamente habituada a hacerlo, sin dañarlo, hasta que él chillara con ronca ternura, como en tales circunstancias siempre lo hizo: “iDéjate, déjate perra, perra brava!" (27). La animalidad que se le atribuye a la mujer sirve para contrastar la diferencia genérica mediante la cual, a modo de contraposición, se logra realzar la virilidad del sujeto masculino: “tenía él un modo sutil y único de decirle 'perra' a la mujer. Ella adoraba más que nunca esa voz cuando la llamaba así: ‘Perra!', con 
todas sus letras, pero con qué musicalidad y armonía de voz" (27). La complementariedad de ambas caracterizaciones indica que la mujer posee un profundo arraigo con el cuerpo, mientras que en contraposición, el varón evidencia apego con la palabra. Estas diferencias implican la constante aparición de opuestos complementarios en la narrativa de Nicomedes Guzmán, donde la mujer tiende a asumir roles que a menudo indican complacencia, respeto y admiración hacia el sujeto masculino.

En "La jauría" (1954) también se advierte la relación que el escritor realiza entre la mujer y la "perra". La narración muestra la atormentada vida de Doralisa Canales quien sufre a diario por los comentarios malintencionados que realiza un grupo de mujeres en el conventillo. De este cuento, resulta interesante observar cómo el escritor consigue retratar la dinámica insidiosa y malintencionada de las mujeres para sí mismas: "Allí estaban las comadres dándole suelta a la lengua [...] Se helaban los rostros y se mojaban las ropas de las hembras. Sus palabras se desparramaban con una constancia insidiosa, espesas insinuaciones [de odio] (114)". Las mujeres aquí reunidas son mostradas desde una evidente animalidad. No por otra cosa la condición de grupo de las proletarias, a diferencia de los varones, resulta una compleja red de complicidades y desavenencias que contribuye a la conformación de la imagen femenina signada en "una figura bestial", cuyas características son la crueldad, "la muerte y la regeneración" (Guerra, "El personaje" 8). Regeneración que según el imaginario de Guzmán y tal como se analizará más adelante, solo puede realizarse mediante la maternidad.

En efecto, las mujeres problematizan la supuesta condición gregaria del proletariado pues, atendiendo a su estrecha relación con el cuerpo, pareciera que estas privilegian el instinto antes que los principios de grupo. Desde esta perspectiva, el hembrismo aquí retratado permite dilucidar un imaginario masculinista que muestra, al igual que las tragedias griegas, la aparente condición pre-política de la mujer, es decir, la exacerbación del instinto femenino por sobre la razón, condición que en apariencia no le permitiría la organización entre pares y de ahí la imposibilidad de organización política. Sin embargo, será en estos mismos relatos, como en otros cuentos y novelas del escritor, que el instinto femenino pareciera huir de la mera animalidad para devenir 
en la conformación de una subjetividad que surge con la maternidad y la relación con los otros.

El escritor pone en tensión la lectura hembrista hasta aquí desarrollada para mostrar cómo la maternidad, en tanto instinto, también posibilita la comunidad y la acción política. Así pues, en "Rapsodia en luz menor", Gabriela es capaz de transformar su dolor, su rabia y su pasividad femenina solo tras encontrarse y reconocerse en otras maternidades. Ante la muerte de la amante de su marido al "dar a luz", Gabriela toma su lugar de madre sin pensarlo, superando la distancia entre los cuerpos femeninos para comprometerse, tras la presencia vital de una nueva vida, en el encuentro con esa otra madre y las otras madres presentes en el velorio. El narrador indica: "un olor dulce a leche, es decir, un olor a vida venció de pronto el olor a sebo de las velas" (136). Gabriela olvida su despecho ofreciendo su pecho a la criatura recién nacida: "mientras la pequeña succionaba y la leche afluía de su cuerpo de hembra para llenarle la rosada boquita infante [...] nada más no había palabras" (136).

La maternidad de la mujer se visualiza aquí como el más puro y transgresor de los sentimientos. Una muestra sublime de ternura que supera cualquier atisbo de individualismo. El cuerpo materno de la mujer exhorta la sociabilidad de la proletaria con los otros o, mejor dicho, con las otras mujeres, visibilizando así nuevas estructuras colectivas desde la maternidad. Esta situación también se observa en el cuento "La jauría" cuando, finalmente, Doralisa castiga a la amante de su marido, Paulina. Más allá de relatar una escena de violencia tras el conflicto pasional surgido entre las mujeres, Nicomedes Guzmán propone a la maternidad como un punto de fuga que rompe con la hostilidad entre ambas. Tras los golpes recibidos por Doralisa, Paulina yace en el suelo a punto de parir: "de repente, las sombras parecieron aclararse. Entre los pies que todavía no dejaban de patear aquel cuerpo retorcido y quejoso, unos ojos se fijaron en los muslos desnudos, vibrantes y espasmódicos, cubiertos de sangre, y en el vientre congestionado" (117). Las mujeres sorprendidas por dicho acontecimiento olvidan el odio y la venganza para acudir al encuentro de ese nuevo ser a punto de nacer: "enseguida, el silencio pareció llamar a las almas a una comunión de ternura. Y la lluvia volvió a caer en lentos y tersos orvallos casi tibios, como humanizados por el brotecer de la nueva vida" (117). Será pues, 
en este contexto, que surge el espacio maternal de la colectividad, el cual logra reunir a las mujeres desde su propia diferencia para reconfigurar el instinto desde un nuevo enfoque que, según se ha revisado, aboga por la vitalidad, la esperanza y la comunión.

La maternidad como línea de fuga ${ }^{4}$ permite advertir la relación entre maternidades y su devenir comunitario como una nueva Bildungsroman social, esto es, el proceso que transforma al yo-individual en yo-comunitario. Este término, según Barbara Foley, solo ha sido utilizado por teóricos como Lukács o Goldmann para analizar el proceso de consciencia social que atraviesan, en la literatura, los diferentes "héroes proletarios" (322). La maternidad, en este sentido, posibilita a la mujer producir colectividad y, al mismo tiempo, fraternidad o mejor dicho sororidad entre las madres proletarias. De igual forma, la maternidad también permite la acción política, en tanto posiciona al cuerpo y sus necesidades como estandarte de lucha, exhortando a las mujeres a trasgredir el espacio y salir de sus hogares en búsqueda de soluciones que apacigüen el hambre y la miseria de su familia.

En La sangre y la esperanza la maternidad es precisamente la condición natural que exhorta a las mujeres a realizar acciones políticas. Al final de la novela, en el apartado "La sangre", se describe una multitudinaria huelga de los desplazados del norte a la que se suman los tranviarios capitalinos, incluido Guillermo Quilodrán, el padre de Enrique. El narrador da cuenta de la situación: "solo hombres llenaban las calles. [...] El depósito, como en la huelga pasada, estaba resguardado por la policía [...] las mujeres se inquietaron. Ellas no estaban con estas cosas. El aire revolucionario las atemorizaba. Las llenaba de miedo" (285). Las mujeres parecieran no responder al llamado revolucionario, pues al no estar involucradas en el discurso y, desde luego, no conocer

\footnotetext{
4 Estas líneas de fuga, en términos de Gilles Deleuze y Claire Parnet (2004), permiten hacer huir a la escritura, es decir, redistribuir "los posibles" y reajustar el espaciotemporal de la existencia (Zourabichvilli 53). Para el filósofo Deleuze, "la línea de fuga es precisamente una desterritorialización" (45), vale decir, "el movimiento por el cual se abandona el territorio" (Deleuze y Guattari 634), el movimiento por el cual se logra perforar a las dicotomías, abrir las polaridades y los dualismos hacia la multiplicidad. En este caso, el cuerpo femenino actúa como línea fuga, toda vez que este, mediante la maternidad, permite superar el supuesto individualismo y la pasividad de la mujer proletaria para devenir en multitud y en acción política.
} 
el argumento ideológico, se muestran reticentes a las manifestaciones, comprendiendo el peligro que deviene de ellas. Sin embargo, resulta interesante observar que posteriormente serán estas las que dejan el miedo y salen a las calles cuando la necesidad vital del alimento azota ferozmente los hogares:

Mujeres de rostros doloridos, de algodonosos pechos pesadamente saltones, de doblegados moños, con los pequeños a la rastra, en brazos u ovillados germinando en el agrio cántaro del vientre. Chiquillos de terrosas cabelleras, de rostros ennegrecidos por añejas mugres. Todos, en fila de parias, marchaban al encuentro de una palabra para encender su esperanza. Allí, marchando, hablando, gesticulando, eran como extraños animales desnutridos, buscando una razón de vida. (294)

La marcha pública de los cesantes, en esta oportunidad, no distingue género. La necesidad impulsa a las mujeres a dejar los albergues, las piezas del conventillo o del cité y los precarios "ranchos" para insertarse en las calles exigiendo pan y trabajo: "Adelante, las mujeres se dieron pronto al canto: los burgueses habitan un mundo, por eternos fulgores vestidos, y los pobres se mueren de frío, en sus chozas sin lumbre y sin pan" (cursivas en el original 294). La necesidad es, en este contexto, aquello que empuja a las mujeres a transgredir el espacio público que usualmente ha sido delimitado para los varones. Las mujeres se agrupan en las calles, aún sin hacer propio el discurso político, con la intención de demandar respuestas ante la carencia de techo, abrigo y alimento para sus familias. Desde la perspectiva de Hannah Arendt, el discurso es esencial para la acción política pues la necesidad, por el contrario, "coloca a los hombres bajo el imperio absoluto de los cuerpos" (93), siendo de este modo profundamente constrictiva para alcanzar la finalidad de la política que, según la autora, será "la liberación de los hombres y de sus semejantes [...] [y no] la liberación del proceso vital de la sociedad de las cadenas de la escasez" (100). Es interesante entonces considerar que los cuerpos femeninos en reunión también actúan políticamente al hacer propio el espacio público demandando intereses que, históricamente, se han catalogado como privados o domésticos. La acción conjunta de las mujeres (de los cuerpos de mujeres) implica la presencia de un nosotros que propone reivindicación todavía sin desplegar un discurso "político". 
Judith Butler propone pensar los cuerpos en conjunto dentro de un espacio público como la expresión reivindicativa de un nosotros. Mediante la persistencia de su exposición, los cuerpos pueden $h a-$ blar políticamente toda vez que, mediante su gestualidad, "adoptan la forma de actuaciones y exigencias" (87) que expresan un mensaje claro y evidente: el descontento, la crisis y la carencia. Butler, a diferencia de Arendt, propone leer los cuerpos en acción desde una manera discursiva, pues el cuerpo al insistir en su visualización en la vía pública "expresa su modo de vida, mostrando tanto su precariedad como su derecho a la persistencia" (87). Así pues, la exposición de los cuerpos en la calle será la búsqueda y la exigencia de las propias condiciones que proporcionan su preservación, convirtiendo entonces las necesidades básicas en cuestiones fundamentales para la política.

La exposición multitudinaria de los cuerpos en la vía publica tendrá por finalidad, cuestionar la legitimidad del Estado y su forma de operar. De ahí que, usualmente, las autoridades se esfuercen en combatir y reprimir las expresiones de dichos cuerpos. Esta situación se muestra en la novela mediante la masacre de los niños y mujeres que constituían el conjunto de cuerpos en manifestación. El narrador da cuenta de la compleja situación: "Las mujeres aullaban, rodando con los hijos, estallando en llanto [...] no cesaban de chillar las mujeres, alzando a sus hijos, clamando piedad" (297). El ejercicio de la autoridad se refleja en la novela como una forma salvaje de arremeter contra la multitud. En este contexto, serán las mujeres y los niños quienes recibirán, mayoritariamente, el peso de la autoridad. No por otra razón son ellas quienes luego salen nuevamente a las calles exigiendo justicia, más aún, organizando crueles actos de "venganza":

Al día siguiente, el barrio se atronó de alaridos [...] las mujeres se desparramaban por las calles, con sus tiras y sus lágrimas, gritando a todos los vientos, para el oído de los asesinos y del mundo: — ¡Abajo los comeguaguas!, —iAbajo los comeguaguas!,... Y los vientos respondían a la aspiración de las hembras miserables, alistando sus más sonoros clarines [...] por muchos días, los guardianes no se atrevieron a andar solos por el barrio. Las mujeres albergadas habíanse convertido en fieras. Dispuestas al crimen para vengar el tremendo crimen. Y más de una madrugada se supo de 
algún policía encontrado con las tripas al aire, tirado a la orilla de una cuneta. (300)

La maternidad herida de las mujeres proletarias es el impulso que las incita a transgredir la ley para reclamar por sus hijos y esposos asesinados. Las mujeres, tal como en Antígona, parecieran actuar en el intersticio que surge entre lo público y lo privado, o más aún, entre lo político y lo pre-político. Los cuerpos femeninos, en su conjunto, transgreden y subvierten la pasividad, el temor y la abulia con que de antaño se esbozaba a los personajes femeninos. Esto considerando que las mujeres, aun desde la necesidad y la venganza, logran reunirse, organizarse y sublevarse ante el orden establecido. En efecto, la maternidad se presenta como una línea de fuga ante la visión masculinista del hembrismo, esto es, una fisura al "rol de dominada" (Sendón de León 44) que reproduce la mujer proletaria en gran parte de las novelas de Guzmán. Atendiendo al giro político del cuerpo, la maternidad exhorta a las mujeres, a la comunidad femenina, a la multiplicidad, a la sororidad. Es decir, una Bildungsroman social femenina que hace transitar a la mujer de su individualidad a la comunidad. La maternidad incita a las mujeres a transgredir el espacio público, a manifestarse políticamente e incluso a infringir la ley. En ambos casos, la convergencia radica en el cuerpo. Las mujeres proletarias que esboza Nicomedes Guzmán parecieran no tener voz, argumento ni discurso que las posicione como sujetos revolucionarios que trabajen a la par con los varones en la reivindicación de clase, sin embargo, será el cuerpo el que "narrated through a maternal language that holds the possibility of historicity even as more [of the political action]" (Rabinowitz 97). En definitiva, el cuerpo femenino deviene comunión, deviene lucha y, desde luego, deviene multitud.

\section{A modo de conclusión}

La narrativa de Guzmán se sustenta en diversas bases ideológicas, estéticas y culturales que le permiten adentrarse, aún más, en el carácter "representativo" de la realidad, dando a conocer la intimidad del pueblo obrero desde dentro. Su escritura, basada muchas veces en su propia experiencia, no se limita a la mera mímesis o al simple hecho de revelar los sucesos ocurridos en los contornos del margen social, sino que por el contrario, se caracteriza por proponer nuevas posibilidades 
de realidad, es decir, por intervenir activamente en la reconfiguración de las sensibilidades y, desde allí, intervenir en la realidad. Así pues, lejos de una intencionalidad documentalista o meramente partidista, el propósito del escritor se orienta a la configuración de un nuevo planteamiento estético-político que reconfigure la noción de pueblo y literatura. Desde esta perspectiva, se comprende la importante presencia de las mujeres proletarias en su narrativa. Estas son vistas por el escritor como interesantes figuras que, constantemente, fueron oscurecidas por la escritura ligada al canon. No por otra cosa Guzmán las incluye en sus cuentos y novelas con la intención de mostrar aquello que, ensombrecido por los vicios del pueblo, no captó la atención de las grandes literaturas nacionales. En este sentido, se comprende que las mujeres se conviertan en una parte fundamental de su narrativa, pues será mediante su presencia que el escritor logrará visualizar los rasgos más nobles y virtuosos del pueblo anónimo.

Considerando, entonces, desde dónde escribe Nicomedes Guzmán es que se ha querido analizar cómo el escritor configura literariamente a la mujer proletaria. Así, se logra advertir cómo el signo mujer proletaria se articula desde las valoraciones genérico-culturales de la época, relacionándose al mismo tiempo con distintas variantes ideológicas, políticas y estéticas que hábilmente el escritor concita en su literatura. De ahí que se han logrado escenificar tres figuras fundamentales que se advierten en su narrativa, a saber, la madre sublime, la compañera-obrera y la prostituta. De este diagnóstico, y como punto en común entre los estereotipos femeninos planteados, se atendió al hembrismo como la concepción genérica-cultural que exhorta a considerar la conexión que tiene la mujer con su cuerpo y con la maternidad. Desde una perspectiva propositiva, el cuerpo y la maternidad se consideró como una línea de fuga, pues en todas las obras de Guzmán es precisamente la maternidad aquello que permite a la mujer salir de su individualismo y devenir en comunidad, algo que aquí se denominó como una Bildungsroman social femenina. En esta línea de análisis, la maternidad como línea de fuga también será relacionada con la agencia política y la transgresión de los espacios. La dicotomía entre lo público y lo privado desaparece una vez que las mujeres salen a la calle en busca de soluciones que mitiguen la carencia de pan y trabajo. Tanto en la labor obrera como en las huelgas multitudinarias, 
la mujer, en tanto madre, lograr romper con la pasividad, el temor y la indiferencia con que de antaño había sido representada en las letras nacionales. En efecto, ante una tradición literaria que enmudeció e invisibilizó a las mujeres del "bajo pueblo", la mujer proletaria se presenta, entonces, como la gran figura radical y disruptiva en la propuesta narrativa de Nicomedes Guzmán.

\section{Referencias bibliográficas}

Álamos Mubarak, Camila. "Madres y putas: degradación corporal y cosificación de la mujer en "La sangre y la esperanza" de Nicomedes Guzmán”. Tesina. Universidad Alberto Hurtado, 2015.

Amaro, Lorena. "Fatalidad y libertad". Brunet, Marta. Obra narrativa. Tomo I. Ed. Natalia Cisterna. Santiago de Chile, Ediciones Alberto Hurtado, 2014, pp. 75-80

Arendt, Hannah. Sobre la revolución. Madrid, Alianza, 2013.

Butler, Judith. Cuerpos aliados y lucha política. Hacia una teoría performativa de la asamblea. Buenos Aires, Paidós, 2017.

Deleuze, Gilles y Guattari, Félix. Mil mesetas. Madrid, Pre-textos, 2002.

Deleuze, Gilles y Parnet, Claire. Diálogos. Valencia, Pre-textos, 2004.

Fernández Smits, María Paz. Amor a palos. La violencia en la pareja en Santiago (1900-1920). Santiago de Chile, LOM Ediciones, 2011.

Foley, Barbara. Radical representations. Politics and form in U.S. Proletarian fiction. Durham, Duke University Press, 1993.

Guerra Cunningham, Lucía “El personaje literario femenino y otras mutilaciones". Revista Hispámerica, vol. 15, no. 43, 1986, pp. 3-19.

Guerra, Lucía."El conventillo: signo del desecho y signo híbrido en Los hombres oscuros de Nicomedes Guzmán". Anales de Literatura Chilena, no. 1, 2000, pp. 117-134.

. La mujer fragmentada. Historias de un signo. Santiago de Chile, Cuarto propio, 2006.

Guzmán, Nicomedes. "Destello en la bruma” en Donde nace el alba: novelas breves. Santiago de Chile, Orbe, 1944, pp, 81-97.

"Rapsodia en luz mayor" en La carne iluminada. Santiago de Chile, Ediciones Amura, 1945, pp, 15-59.

. La luz viene del mar. Santiago de Chile, Zig-Zag, 1963. 
"La jauría" en El Pan bajo la bota. Santiago de Chile, Zig-zag, 1963, pp,107-117.

. La sangre y la esperanza. Santiago de Chile, LOM Ediciones, 2014.

. Los hombres oscuros. Santiago de Chile, LOM Ediciones, 2014.

Juliano, Dolores. Tomar la palabra: mujeres, discursos y silencios. Barcelona, Edicions Bellaterra, 2017.

Montero, Susana. La construcción simbólica de las identidades sociales. México D.F, Universidad Nacional Autónoma de México, 2002.

Pearson, Lon. Nicomedes Guzmán. Proletarian author in Chile's literary generation of 1938. Missouri, University of Missouri Press, 1976.

Rabinowitz, Paula. Labor \& desire: Women's fiction in depression America. North Carolina, The University of North Carolina Press, 1991.

Rosemblatt, Karin. Gendered compromises. Political cultures and the state in Chile, 1920-1950. North Carolina, The University of North Carolina Press, 2000, pp, 185-189.

Sendón de León, Victoria. “Coeficiente simbólico femenino". Género y comunicación. Ed. Juan Plaza y Carmen Delgado. Madrid, Fundamentos, 2007, pp. 44-45.

Schaefer, Richard. Ed. Encyclopedia of race, ethnicity and society. California, Sage Publications, 2008.

Žižek, Slavoj. El sublime objeto de la ideología. Madrid, Siglo XXI, 2001.

Zourabichvili, François. Deleuze, una filosofía del acontecimiento. Buenos Aires, Amorrortu, 2004. 